\title{
Musculoskeletal Disorders in Caregivers of Children with Cerebral Palsy Following a Multilevel Surgery
}

\author{
Deepak Sharan ${ }^{1}$, Ajeesh PS ${ }^{1}$, Rameshkumar R ${ }^{1}$, Manjula.M ${ }^{1}$ \\ Address for correspondence: ${ }^{1}$ RECOUP Neuromusculoskeletal Rehabilitation Centre, Bangalore, India.
}

\begin{abstract}
The patients of cerebral palsy need assistance for their self activities which expose the caregivers to different risk factors of musculoskeletal disorders. But there is a scarcity of studies revealing the prevalence and the risk factors present among the caregivers of the cerebral palsy children. This lead to formulate a study to identify prevalence and risk factors among the caregivers of cerebral palsy children. Result revealed that most of the caregivers among both the groups were female $(63.4 \%$ and $69.3 \%$ ). The common age group of the children who underwent multilevel surgery was at the age group of $6-10$ years. It has been observed that among the study group $56.5 \%$ were totally cooperative children. The Caregiver Strain Index value showed there is no significant difference among both the groups. Regional body pain of shoulder, elbow, upper back, lower back and ankle revealed a higher prevalence among the study group. Clinical diagnosis revealed prevalence of MPS, FMS and TOS among the study group were $27.6 \%, 24.5 \%$ and $23.0 \%$ respectively. Study further revealed that cooperativeness of the child was significantly associated with lower back pain, MPS, FMS and TOS among the study group.
\end{abstract}

Keywords: "Modified Care givers Strain Index" "visual analog scale" "Lifting and carrying"

\section{Introduction}

Musculoskeletal Disorders (MSD) such as pain in back, shoulder, knee etc. are common in fulltime caregivers [11]. Prevalence of back pain among health professionals, nurses and physiotherapist, has been studied extensively in their occupational settings. The causes were found to be repetitive heavy lifting and carrying, maintaining awkward posture for long duration, ignorance of own health issues, less reporting of musculoskeletal injury and attaining many patients in a single day. Cerebral palsy is an umbrella term encompassing a group of non-progressive [14,15] non-contagious motor conditions that cause physical disability in human development, chiefly in the various areas of body movement [1]. Cerebral palsy's nature as an umbrella term means it is defined mostly via several different subtypes, especially spastic, and also mixtures of those subtypes. Cerebral palsy is caused by damage to the motor control centers of the developing brain and can occur during pregnancy, during childbirth or after birth up to about age three [16,17]. All types of cerebral palsy are characterized by abnormal muscle tone (i.e. slouching over while sitting), reflexes, or motor development and coordination.

There can be joint and bone deformities and contractures (permanently fixed, tight muscles and joints). The classical symptoms are spasticities, spasms, other involuntary movements (e.g. facial gestures), unsteady gait, problems with balance, and/or soft tissue findings consisting largely of decreased muscle mass. Due to all these above mentioned reasons the child suffering from cerebral palsy are unable to make move, do their selfactivities by themselves. They need assistance to do all daily activities and for movement as well. The parents or health care professional who involve to handle such patients need to exert themselves in different awkward posture, holding the child/patient for long duration and many other risk factors that may cause the development of musculoskeletal 
disorders. During the treatment period such as after multilevel surgery or during in any therapy sessions lifting and carrying expose the caregivers (parents or health care professional) to heavy physical load. There are studies which explain prevalence, incidence, and risk factors of musculoskeletal disorders among different health care professionals. But there is scarcity of the study which gives proper understanding of the risk factors, rate of prevalence and incidence of the musculoskeletal disorders among the caregivers of the patients who are suffering from cerebral palsy. Therefore, a need is felt to find out the prevalence \& type of MSDs and the body regions affected by MSDs in caregivers along with the risk factors. Keeping this in mind a study was formulated with following objective

- To identify the prevalence, affected body regions affect by MSD among caregivers of postoperative (study group) and non operative (control group) children with cerebral palsy.

- To find out the probable risk factors to develop MSD among the caregivers.

\section{Methodology}

\subsection{Study design and sample}

This study used quantitative methods using a cross-sectional descriptive survey by purposive random sampling. Participants were two groups of subjects participated in this study. First group comprised of 257 caregivers who were parents and caregivers of children with $\mathrm{CP}$ who underwent multilevel surgery. Both male and female parents were recruited from the RECOUP to participate in the study based on the inclusion and exclusion criteria. The second group comprised of 117 caregivers of ambulatory children with other orthopedic problems such as clubfoot and other deformities, such as spina bifida. Care givers like father, mother and close relatives who were doing nursing care including activities such as assistants in movements, excretory function, feeding skin care bathing and caring the child to the rehabilitation centre for therapy are included in the Study.

\subsection{Inclusion Criteria}

- Caregivers of children with CP who were undergoing postoperative rehabilitation following multilevel surgery.

\subsection{Inclusion criteria for control group}

- Caregivers of ambulatory children with other orthopedic problems such as clubfoot and other deformities, such as spina bifida.

\subsection{Exclusion criteria}

- History of back surgery or fracture.

- Caregivers younger than 18 years.

- Caregivers with children below 2 years of age were excluded because they needed to be carried.

- Caregivers caring for more than one child with disabilities.

- Caregivers other than primary caregiver of child.

\subsection{Materials and instruments}

The study utilized a closed ended self-administered questionnaire. The questionnaire consisted of 10 closed ended questions. The self evaluation questionnaire include questions regarding demographic factors such as age, sex, BMI, level of independence of the child, cooperativeness of the child, the level of sleep disturbance and mental stress were measured by visual analog scale (VAS). The level of physical exertion during lifting/carrying child and fatigue were measured using Borg CR-10 scale, and the Modified Caregiver Strain Index (CSI) is a tool that can be used quickly for caregiver strain with long-term family caregivers. It is a 13-question tool that measures strain related to care provision. There is at least one item for each of the following major domains: Employment, Financial, Physical, Social, and Time. This instrument can be used to assess individuals of any age who have assumed the role of caregiver for an older adult. The Modified Caregiver Strain Index is a version of the Caregiver Strain Index developed in 1983 [10]. Scoring is 2 points for each 'yes', and 1 point for each 'sometimes' response. The higher the score, the higher the level of caregiver strain. Internal reliability coefficient is slightly higher (alpha $=0.90)$ than the coefficient originally reported for the CSI in 1983 (alpha $=0.86$ ). Caregivers were informed that the purpose of the study was to identify obstacles they experience during the post operative rehabilitation phase after multilevel surgery. Caregivers were asked to give their consent to participate in the study. Each subject took 10-12 minutes to complete the questionnaire.

\subsection{Data analysis}


All the responses obtained from the parents were coded numerically and entered into the SPSS version 18.0 software program for analysis. Descriptive statistical analysis was used to calculate the frequencies and percentages. The descriptive analysis of data presented as figures and tables. Results on continuous measurements are presented on Mean $( \pm \mathrm{SD})$ and results on categorical measurements are presented in Number (\%). Student t test (two tailed, independent) has been used to find the significance of study parameters on continuous scale between two groups and inter group analysis. Chi-square has been used to find the significance of study parameters on categorical scale.

\section{Result}

Descriptive analysis of the demographic data indicated that $63.4 \%$ and $69.3 \%$ of Caregivers were females in the study and control group respectively and the data were presented in Table $\bullet \bullet$

Table 1.

Age and Gender Distribution of Caregiver in the study

\begin{tabular}{lll} 
& and control group & \\
\hline $\begin{array}{l}\text { Study Group } \\
\text { (N=257) }\end{array}$ & Number & Percentage \\
\hline Male & 94 & $36.6 \%$ \\
\hline Female & 163 & $63.4 \%$ \\
Mean Age & $35.4 \pm 6.73$ & \\
$\begin{array}{l}\text { Control Group } \\
\text { (N=117) }\end{array}$ & & \\
Male & 36 & $30.7 \%$ \\
\hline $\begin{array}{l}\text { Female } \\
\text { Mean Age }\end{array}$ & 81 & $69.3 \%$ \\
\hline
\end{tabular}

It also has been observed that the common age group of children who underwent multilevel surgery (i.e. control group) were at the age 6-10 years and the distribution is presented in Table 2 .
Table 2.

Age Distribution of Child according to the Gender in the study and control group

\begin{tabular}{lllll}
\hline $\begin{array}{l}\text { Age } \\
\text { (years) }\end{array}$ & \multicolumn{3}{c}{ Study group } & \multicolumn{3}{l}{ Control group } \\
\hline & Male & Female & Male & Female \\
\hline$<5$ & $13.22 \%$ & $10.11 \%$ & $15.3 \%$ & $4.27 \%$ \\
\hline $6-10$ & $29.57 \%$ & $20.62 \%$ & $21.36 \%$ & $19.65 \%$ \\
\hline $11-15$ & $14.00 \%$ & $9.72 \%$ & $8.54 \%$ & $16.23 \%$ \\
\hline$>15$ & $0.77 \%$ & $0.38 \%$ & $10.25 \%$ & $4.27 \%$ \\
\hline $\begin{array}{l}\text { Mean } \pm \\
\text { SD }\end{array}$ & $8.5 \pm 3.4$ & & $10.32 \pm 4.93$ & \\
\hline
\end{tabular}

$56 \%$ of the Children in the study group were totally non cooperative, and $28 \%$ of the child was partially Cooperative which is represented in Figure 1 , whereas, all the children in the control group were fully cooperative.

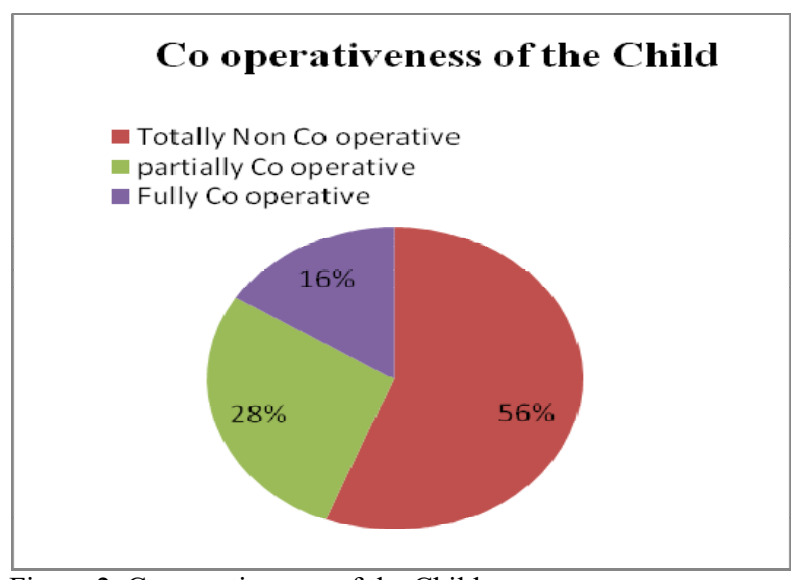

Figure 2. Cooperativeness of the Child

The common Musculoskeletal Disorders identified were Myofascial Pain Syndrome (27.6\%), Fibromyalgia syndrome (24.5\%) and Thoracic Outlet Syndrome (23\%) among the study group.

The result of caregiver strain index is presented in Table 3. 
Table 3.

Mean of Modified Strain Index Score

\begin{tabular}{ll}
\hline Group & $\begin{array}{l}\text { Mean of Modified Caregiver } \\
\text { Strain Index }\end{array}$ \\
\hline Study Group & $10.08 \pm 5.23$ \\
Control Group & $9.37 \pm 6.60$ \\
\hline
\end{tabular}

It has been observed that the mean value of the Caregiver strain index is similar for both the groups $(\mathrm{t}-1.13 \mathrm{p}>0.05)$.

Analysis of sleepless revealed that the study group has higher level of sleeplessness as compared to control group ( $\mathrm{t}-4.27, \mathrm{p}<0.001)$. Similar result was also found for the responses of fatigue (t-9.16, $\mathrm{p}<0.001)$ represented in Table 4.

Table 4.

Mean of Modified Strain Index Score

\begin{tabular}{lll}
\hline Group & Sleeplessness & Fatigue \\
\hline t-vale & 4.27 & $\mathrm{P}<0.001$ \\
\hline Level of significance & 9.16 & $\mathrm{P}<0.001$ \\
\hline
\end{tabular}

The Table 5 represent a comparison of regional body pain among both the groups. The result revealed that the prevalence of body region discomfort for shoulder, elbow, upper back, lower back and ankle are significantly higher for the study group as compared with control group.

Table 5.

Prevalence of Pain in both groups

\begin{tabular}{lllll}
\hline \multirow{2}{*}{ Body parts } & \multicolumn{2}{c}{ Control Group } & \multicolumn{2}{c}{ Study Group } \\
\cline { 2 - 5 } Shoulder* & Pain & No-pain & Pain & No-pain \\
\hline Elbow* & $18.80 \%$ & $81.20 \%$ & $42.02 \%$ & $57.98 \%$ \\
\hline Hand & $31.62 \%$ & $68.38 \%$ & $21.79 \%$ & $78.21 \%$ \\
\hline Upper back* & $20.51 \%$ & $79.49 \%$ & $39.69 \%$ & $60.31 \%$ \\
\hline Lower back* & $35.59 \%$ & $64.41 \%$ & $55.64 \%$ & $44.36 \%$ \\
\hline Knee & $27.35 \%$ & $72.65 \%$ & $27.63 \%$ & $72.37 \%$ \\
\hline Ankle* & $0 \%$ & $100.00 \%$ & $15.95 \%$ & $84.05 \%$ \\
\hline
\end{tabular}

* -Significant difference

\subsection{Correlation}

The relationship between the cooperativeness of the child and the regional body pain and clinical diagnosis of the caregiver is presented in Table 6.

Table 6.

Relationship between Cooperativeness of the child and Caregiver's Regional body pain \& Clinical Diagnosis

\begin{tabular}{|c|c|c|}
\hline & $\chi^{2}$ value & $\begin{array}{l}\text { Level of } \\
\text { significance }\end{array}$ \\
\hline \multicolumn{3}{|c|}{ Regional body pain } \\
\hline Shoulder & 4.98 & $\mathrm{P}<0.08$ \\
\hline Upper back & 2.49 & $\mathrm{P}<0.28$ \\
\hline Lower back* & 10.67 & $\mathrm{P}<0.004$ \\
\hline Knee & 3.03 & $\mathrm{P}<0.21$ \\
\hline \multicolumn{3}{|c|}{ Clinical Diagnosis } \\
\hline MPS* & 19.34 & $\mathrm{P}<0.001$ \\
\hline FMS* & 26.08 & $\mathrm{P}<0.002$ \\
\hline TOS* & 14.89 & $\mathrm{P}<0.006$ \\
\hline
\end{tabular}

The above table revealed that the cooperativeness of the child is significantly associated with lower back pain, MPS, FMS and TOS of the caregiver among the study group. The association could not be established among the control group, as all the children in that group were fully cooperative.

\section{Discussion}

In this study, caregivers reported a number of difficulties they met in complying with the treatment regimen. These include financial difficulties, a lengthy distance from home to the hospital, lifting and carrying the child during the rehabilitation, lack of family support and lengthy waiting time at the clinics. However, most parents reported financial constraints to meet transport costs and mental stress as potential difficulties they encountered during rehabilitation treatment regimen. The pathomechanics leading to back pain most of the time is believed to be the repetitive lifting of children, considering the fact that parents are lifting an average of 20 -25 Kilogram children 10-15 times per day [2, 9]. It is very important to give a safe and careful care to the child after multilevel surgery. Work and stress in the family aside, studies show that parenthood of disabled child is a proven risk factor for back problems in both male and female [14]. Even though 
the loads are relatively light, unknowingly it increases the compression force in the low back and the repetition of movement that gets the condition worse [2-9]. All the parents hold their child in an upright position, directly against the chest in the centre. Carrying a child in this position creates postural imbalances that can lead to low back pain and other musculoskeletal disorders over the time. The lifting height is from the floor to shoulder height and maximum acceptable weight of lift for males for one lift every 30 minutes is $23 \mathrm{Kg}$ for $90 \%$ of population and for females is $14 \mathrm{~kg}$ [9]. The average weight of the children is higher than maximum acceptable weight [4-9]. It directly increases the physical stress and ends in MSD's. Fibromyalgia syndrome is frequently associated with chronic fatigue, poor sleep, irritable bowel, headaches and other vegetative symptoms [2, 4-11, 13-17]. Repetitive bending and lifting will lead to produce myofascial pain syndrome in lower back and upper back and other body parts. During heavy lifting, isometric contraction of the neck muscles, repetitively contraction of neck muscles will produce compression of soft tissues like nerves and blood vessels lead to produce Thoracic out let syndrome (TOS). Chronic pain and stress lead to produce fibromyalgia [4-8]. Early identification of these MSDs and treatment of the same is essential to prevent them from becoming severe cases of MSDs.

\section{Conclusion}

The results indicated a significant prevalence of pain and discomfort in caregivers of children with cerebral palsy; we recommend routine training in safe transferring, lifting and carrying techniques to all parents and care givers during the preoperative period. In addition, psychological counselling, stress management and training regarding sleep hygiene are recommended. As the study result revealed no significance difference of caregiver strain index between both the groups and high prevalence of MSD among the study group, it is obvious that the caregiver strain index doesn't confer the risk factors of MSD among the caregivers. Therefore a need was felt to formulate a study to develop a risk assessment questionnaire which gives a proper indication about the MSD risk factors among the caregivers of the Cerebral Palsy children.

\section{References}

[1] Beukelman, D.R., Mirenda P., Augmentative and Alternative Communication: Management of severe communication disorders in children and adults (2nd ed.). Baltimore: Paul H Brookes Publishing Co., 1999, 246-249.

[2] Cheng Te-Shiang and Tzu-Hsien L.E.E., Maximum acceptable weight of lift for asymmetric lifting; Perceptual and motor skills, 2003, 96, 1339 - 1346.

[3] Hefferin E.A., Hill B.J., Analyzing nursing's workrelated injuries, Am J Nurs, 1976, 76, 924 - 927.

[4] Hong C.Z., Simons D.G., Pathophysiologic and electrophy....siologic mechanisms of myofascial trigger points, Arch Phys Med Rehabil, 1998, 79, 963 - 972.

[5] Hulshof C., van Zanten B.V., Whole-body vibration and low back pain: a review of epidemiologic studies, Int Arch Occup Environ Health, 1987, 59, 205 - 220.

[6] Maurice M., specific characteristics of the pain/ depression association in the general population, $\mathrm{J}$ Clin Psychiatry, 2004, 65, 5-9.

[7] Maurice M., Using chronic pain to predict depressive morbidity in the general population, Arch Gen Psychiatry, 2003, 60, $39-47$.

[8] Pal D.K., Chaundhury G., Sengupta S and Das T. Social integration of children with epilepsy in rural India, Social Science and Medicine, 2002, 54, 1867 - 1874.

[9] Rina M., and Ray G.G., Determination of maximum acceptable weight of lift by adult Indian female workers, International Journal of Industrial Ergonomics, 2004, 34, $483-495$.

[10] Thornton M., Travis S.S., Analysis of the reliability of the modified caregiver strain index., Soc Sci, 2003, 58, S127 - S132.

[11] Tonga E., Düger T., Factors affecting low back pain in mothers who have disabled children, Journal of Back and Musculoskeletal Rehabilitation, 2008, 21, 219 226.

[12] Videman T., Rauhala H., Asp S., Patient-handling skill, back injuries, and back pain: an intervention study in nursing, Spine, 1989, 14, 148 - 156.

[13] Yalcinkaya Y.E., Önes K., Ayna A.B., Turkyilmaz A.K., Erden N., Low Back Pain Prevalence and Characteristics in Caregivers of Stroke Patients: A Pilot Study, Topics in Stroke Rehabilitation, 2010, 17, 389 393.

[14] www.cdc.gov

[15] "cerebral palsy" at Dorland's Medical Dictionary.

[16] http://children.webmd.com/tc/cerebral-palsy-topicoverview. Retrieved 2008-02-06.

[17] WebMD Medical Reference from Healthwise. 